http://dx.doi.org/10.1590/0104.026X2015v23n3p1033

\title{
Vozes no silêncio
}

\section{Da Guerrilha à imprensa feminista: a construção de um feminismo pós-luta armada no Brasil (1975-1980)}

TELES, Amelinha; LEITE, Rosalina Santa Cruz Leite.

$\frac{\text { São Paulo: Intermeios, } 2013 .}{\text { (ㄷ) } \odot \text { Esta obra tem licença Creative Commons. }}$

O século XX é, por muitos, considerado o século das mulheres e, especialmente, do feminismo, ainda que os fundamentos desse movimento remontem ao século XIX. Para Céli Regina Pinto, o movimento feminista constituiu-se para lutar contra uma condição dada historicamente pela desigualdade nas relações em nível público e privado, da razão e do sentimento, do trabalho e do prazer, da obrigação e do desejo. Nesta condição está a radicalidade do movimento, que tem como consequência uma desorganização profunda dos espaços de poder cotidiano.

Naquele momento, a desmistificação da castidade, os contraceptivos e as possibilidades de exercício do prazer e da sexualidade, reivindicados pela revolução sexual, são sintetizados pelo lema "o pessoal é político". No entanto, o movimento feminista no período da Ditadura no Brasil vai além, questionando e pontuando questões silenciadas através das publicações dos jornais Brasil Mulher ${ }^{2}$ e Nós Mulheres,$^{3}$ como ressaltam Amelinha Teles e Rosalina Santa Cruz Leite na obra feita a quatro mãos: Da Guerrilha à imprensa feminista: a construção de um feminismo pós-luta armada no Brasil (1975-1980).

Maria Amélia Teles, mais conhecida como Amelinha, é ex-militante do PCdoB e ex-presa política; integrou organizações da luta armada, contra a ditadura militar no Brasil, e atua como militante feminista em diversas frentes. De 1975 a 1980, fez parte do jornal feminista Brasil Mulher. Foi fundadora da Comissão de Familiares de Mortos e Desaparecidos Políticos e integra, atualmente, a Comissão Estadual da Verdade de São Paulo. Publicou diversos livros sobre as várias possibilidades de experiências do feminismo, entre eles, Breve História do
Feminismo. ${ }^{4}$ Rosalina Santa Cruz Leite possui convergências em suas experiências políticas com Amelinha. Participou como guerrilheira da Vanguarda Revolucionária-Palmares (VARPalmares), é ex-presa política e atuante nas reivindicações feministas da atualidade. Também fez parte do jornal Brasil Mulher e, atualmente, é professora da Pontifícia Universidade Católica de São Paulo, onde também concluiu seu doutorado com a tese $A$ imprensa alternativa pós-luta armada: os jornais Brasil Mulher e Nós Mulheres.

A união dessas duas vivências resulta no título do livro, que é uma referência às autoras e outras mulheres oriundas, em sua grande maioria, de organizações da luta armada e presas políticas que, ao saírem da cadeia, procuraram continuar sua ałuação. Suas organizações tinham sido desfeitas e desmanteladas pela repressão. Assim sendo, organizaram-se em outros movimentos ou aderiram aos que já tinham sido iniciados.

Prefaciado pela historiadora Margareth Rago, este livro constitui um esforço singular, no sentido de entender um "tempo de guerra" e também as experiências de mulheres em busca de direitos, mobilizadas na transformação substantiva da vida cotidiana, como ressaltou Rago.

A obra é dividida em nove capítulos e diversos subtítulos, metodologia que norteia o leitor a compreender a vasta gama de temas que atravessam a ditadura, o cotidiano de resistência e as reivindicações feministas. No final de cada capítulo há capas dos jornais Nós Mulheres e Brasil Mulher, com referência a temas tratados em cada capítulo, o que chama a atenção para as análises dos assuntos prioritários no âmbito feminista e reivindicações das mulheres trabalhadoras da época. Deste modo, as autoras nos transportam, neste estudo, para conjunturas decisivas da história do Brasil, quando ainda vivenciávamos a repressão militar, mas, também quando emergiam os "novos momentos sociais", como o Movimento do Custo de Vida, primeiro movimento de massas pós-Al-5, do qual as mulheres da periferia foram as protagonistas.

Outro exemplo de protagonismo feminino foi a greve de operários que obteve participação ativa de Conceição Imaculada de Oliveira, diretora do Sindicato dos Metalúrgicos de Contagem, descrito no Capítulo 1: "Era um tempo de guerra, era um tempo sem sol". O capítulo introduz o leitor ao universo de repressão e resistência no 
Brasil, evidenciando o papel de mulheres até então desconhecidas ou negligenciadas pela historiografia e as barreiras que enfrentaram à sua maneira. Seus testemunhos subjetivam e objetivam a vida logo após os primeiros anos da ditadura. A questão que se faz presente é o rompimento de preconceitos e barreiras não apenas junto à família, mas dentro das próprias organizações de esquerda das quais muitas faziam parte.

O Capítulo 2, "Da guerrilha à imprensa feminista", destaca a organização e atuação de movimentos como o Movimento Feminino pela Anistia, liderado por Terezinha Zerbine como um espaço de surgimento de outras formas de resistência com destaque para o jornal Brasil Mulher, criado em 1975, uma ideia inicial de Joana Lopes, que vivia em Londrina (PR). Joana transformaria o Brasil Mulher em um veículo de ideias feministas, o que levou Zerbine a sair do projeto, pois seu principal foco era a Anistia Ampla Geral e Irrestrita.

O Capítulo 3, "Memorial dos jornais feministas: Brasil Mulher e Nós Mulheres", ilustra as convergências entre ambos os veículos ao serem criados no mesmo momento político, mas demonstra a tendência a cisões entre a atuação política de esquerda do período. Enquanto as atuantes do jornal Brasil Mulher eram oriundas da luta armada, as militantes do Nós Mulheres eram, em sua maioria, brasileiras feministas exiladas em diversos países. As nuances que aproximam e distinguem os dois jornais feministas são bem analisadas pelas autoras.

O Capítulo 4, "Levantamento e análise das matérias publicadas no Brasil Mulher e Nós Mulheres", aprofunda as diferenças e convergências entre ambos através de uma pesquisa documental para elaboração de tabelas e gráficos comparativos. Tal análise desconstrói os jornais, na aspiração de olhá-los em categorias que orientam os temas da conjuntura geral do período, como o Movimento pela Anistia, liberdades democráticas, eleições (1976/78) e temas de interesse imediato das mulheres, tais como: direitos da mulher no campo, reprodução, sexua lidade, aborto, creche, violência doméstica, entre tantos outros.

O Capítulo 5, intitulado "Protagonismo feminista: tensões e ambivalências", está interligado ao Capítulo 6: "Com a palavra, as Protagonistas". Enquanto o primeiro apresenta reflexões teóricas sobre memória e geração, revelando comportamentos e experiências antagônicas das mulheres que participaram dos jornais demonstrando as narrativas singulares sobre os mesmos fatos e acontecimentos, o Capítulo 6, por meio das histórias de vida das participantes de ambos os jornais, pode nos apontar os motivos destas singularidades. São depoimentos esclarecedores de onze mulheres, incluindo as autoras.

O Capítulo 7: "Anistia, custo de vida e eleições" delineia três temas frequentes tratados nos jornais, ocupando espaços destacados e alimentando de forma interna os debates de Brasil Mulher e Nós Mulheres. O tema eleições, por exemplo, permite evidenciar que, até hoje, a participação político-eleitoral partidária das mulheres possui obstáculos a serem superados mesmo que se tenha, pela primeira vez no país, eleita diretamente pelo voto popular para assumi a presidência da República, uma mulher de esquerda e da luta armada nos tempos da ditadura. Assim, falar do passado é também falar do presente.

Inspiradas por Foucault, as autoras analisam a circulação de poder não apenas entre homens e mulheres na militância de esquerda, mas na vivência de mulheres retratadas nos jornais, como Lindonéia, que sente o peso da vida por viver ao lado de "um homem bom", mas por quem não possui atração e amor como pode ser analisado no Capítulo 8: "Nem vítimas, nem cúmplices: o sexo na imprensa feminista". Esta, ao reprimir seus desejos, acaba aceitando o diagnóstico de psicótica maníaco-depressiva e sua internação no Hospital Psiquiátrico do Estado de São Paulo, local de trabalho do marido. Seria uma estratégia de resistência ao sexo obrigatório ou uma punição por não sentir atração pelo esposo, "um homem bom"?

O Capítulo 9, "Questões teóricas do feminismo dos anos 70", apresenta estudiosas que se debrucaram sobre as teorias marxistas para uma análise das mulheres na sociedade de classes, como Heleieth Saffiot e Maria da Glória Gohn, evidenciando a matriz teórica marxista que orientava os estudos sobre a questão da mulher na época e seus opositores. Além disso, esclarecem as leituras que faziam parte do cotidiano das feministas dos anos de 1970, entre elas, Juliet Mitchell, por sua preocupação com os rumos do movimento das mulheres. As autoras encerram o livro com a Conclusão, intitulada: "A imprensa feminista sai do papel e ganha as ruas", destacando o importante papel dos jornais Brasil Mulher e o Nós Mulheres na divulgação e construção de uma nova forma de pensar e viver práticas feministas na sociedade de antanho.

Este livro é uma reflexão sobre como hoje não é fácil definir em que momento termina o passado e começa o presente, como lidamos 
com a imaginação, a memória e a subjetividade em nossas narrativas. As envolventes histórias que perfazem o livro são o resgate de memórias silenciadas e que, hoje, se unem a outros clamores cunhados pelos testemunhos trazidos a público pela Comissão da Verdade. Uma oportunidade de conhecer novas facetas da história do Brasil em tempos de repressão para estudiosos experientes e para os que iniciam seus estudos. Uma fundamental contribuição lançada na Coleção ENTREGÊNEROS, pela editora INTERMEIOS, pensada a partir da junção de experiências e memórias de suas autoras. Trabalho que pode ser lido, ainda, como um ato de militância e de esperança no momento presente.

\section{Notas}

' Céli Regina Jardim PINTO. Uma História do Feminismo no Brasil. São Paulo: Fundação Perseu Abramo, 2003.

${ }^{2}$ Brasil Mulher (1975 a 1980).

${ }^{3}$ Nós Mulheres (1976 a 1978).

${ }^{4}$ Maria Amélia de Almeida TELES. Breve história do feminismo no Brasil. São Paulo: Brasiliense, 1999.

Kelly Cristina Teixeira Universidade Federal de Santa Catarina. 